\title{
Radiographic and clinical factors associated with one-leg standing and gait in patients with mild-to- moderate secondary hip osteoarthritis
}

\section{$\operatorname{AUTHOR}(\mathrm{S}):$}

Tateuchi, Hiroshige; Koyama, Yumiko; Akiyama, Haruhiko; Goto, Koji; So, Kazutaka; Kuroda, Yutaka; Ichihashi, Noriaki

\section{CITATION:}

Tateuchi, Hiroshige ... [et al]. Radiographic and clinical factors associated with one-leg standing and gait in patients with mild-to-moderate secondary hip osteoarthritis. Gait \& Posture 2016, 49: 207-212

\section{ISSUE DATE:}

2016-09

URL:

http://hdl.handle.net/2433/217348

\section{RIGHT:}

(c) 2016. This manuscript version is made available under the CC-BY-NC-ND 4.0 license

http://creativecommons.org/licenses/by-nc-nd/4.0/; The full-text file will be made open to the public on 01 September 2017 in accordance with publisher's 'Terms and Conditions for Self-Archiving'.; この論文は出版社版でありません。引 用の際には出版社版をご確認ご利用ください。; This is not the published version. Please cite only the published version. 


\title{
Radiographic and clinical factors associated with one-leg standing and gait in patients with mild-to-moderate secondary hip osteoarthritis
}

Hiroshige Tateuchi, PT, PhD, Yumiko Koyama, PT, MS, Haruhiko Akiyama, MD, PhD, Koji Goto, MD, PhD, Kazutaka So, MD, PhD, Yutaka Kuroda, MD, PhD, Noriaki Ichihashi, PT, PhD

\begin{abstract}
:
A decline in physical function associated with secondary hip osteoarthritis (OA) may be caused by both radiographic and clinical factors; however, the underlying mechanism remains unclear. The purpose of this study was to determine how joint degeneration, hip morphology, pain, hip range of motion (ROM), and hip muscle strength relate to one-leg standing (OLS) and gait in patients with mild-to-moderate secondary hip osteoarthritis. Fifty-five female patients (ages 22-65 years) with mildto-moderate hip OA secondary to hip dysplasia were consecutively enrolled. Balance during OLS and three-dimensional hip angle changes while maintaining the OLS and at foot-off of the raised leg were measured. Gait speed and peak three-dimensional hip joint angles during gait were also measured. The associations between dependent variables (balance, gait speed, and hip kinematic changes) and independent variables (age, body mass index, pain, joint degeneration, hip morphologic abnormality, passive hip ROM, and hip muscle strength) were determined. While lower hip muscle strength was associated with hip kinematic changes such as flexion and internal rotation while maintaining OLS, decreased acetabular head index (AHI) and increased pain were associated with hip extension and abduction at foot-off in OLS. Decreased passive hip ROM was associated with decreased peak hip angles (extension, adduction, and external and internal rotation) during gait, although increased pain and decreased hip extension muscle strength were associated with slower gait speed. In this study of patients with secondary hip OA, AHI, pain, and hip impairments were associated with OLS and gait independently from age and radiographic degeneration.
\end{abstract}

\section{Keywords:}

Hip; Osteoarthritis; One leg standing; Gait; Acetabular dysplasia 


\section{Highlights}

- No factor was related to the balance measures during static OLS.

- Decreased hip muscle strength was related to hip flexion and internal rotation in OLS.

- Pain and decreased AHI were related to hip abduction and extension at foot-off in OLS.

- Pain and decreased hip extension strength were related to slower gait speed.

- Decreased hip ROM was related to a reduced peak hip angle during gait. 


\section{Introduction}

Acetabular dysplasia resulting in reduced load-transfer areas is a significant risk factor for the incidence and progression of hip osteoarthritis (OA) [1]. Secondary hip OA is more prevalent than the primary form and typically has an early onset [2]. Young individuals are often exposed to high physical loads in their daily life [3]; secondary hip OA progresses joint degeneration and disabilities from a young age. Recently, treatment strategies for hip OA have shifted towards prevention during its early phases, including preosteoarthritis [4]. Investigation of declining physical function is important, particularly in young patients with mild-to-moderate hip OA.

Symptoms and hip impairments such as reduced range of motion (ROM) and muscle strength lead to compromised basic physical functions such as gait [5]. Maintaining balance and joint alignment during standing is also required during housework and standing work; physical work load during standing has been identified as a risk factor for hip OA [6]. Impaired balance and pelvic obliquity during one-leg standing (OLS), and decreased speed and hip joint excursion during gait have been reported in patients with hip OA [7-9]. On clinical examination, positive Trendelenburg's sign was found in $38 \%$ and limp was present in $85 \%$ of patients with acetabular dysplasia [7]. Therefore, exploring the cause of decline in basic physical function such as OLS and gait in patients with hip OA is a critical issue.

A decline in physical function associated with OA progression may be caused by joint degeneration and morphologic abnormalities evident on radiographs and by clinical factors such as symptoms and impairments; however, the underlying mechanism remains unclear. Previous studies have reported relationship between hip extension muscle strength or hip flexion ROM and gait speed [10,11], and between pain or hip abduction muscle strength and hip moment or pelvic and trunk rotation during gait $[12,13]$. However, these previous studies have focused on end-stage hip OA or have included limited factors in their association analyses. To our knowledge, no other studies have comprehensively investigated the factors that influence OLS and gait in patients with hip OA patients before end-stage of disease.

Kinematic changes are directly linked to changes not only in kinetic parameters such as joint moment but also in load-transfer areas, and consequent changes in cartilage contact stress [14]; hence, 
kinematic observation as well as physical performance (i.e., balance during OLS and gait speed) are required for assessment of patients with hip OA. Knowledge of the associations between these variables and basic physical functions may assist clinicians in improving physical function in patients with hip OA. The aim of this study was to determine how various factors including age, joint degeneration, hip morphology, pain, hip ROM, and hip muscle strength relates to performance and hip kinematic changes during OLS and gait in patients with mild-to-moderate secondary hip OA.

\section{Methods}

\subsection{Participants}

Fifty-five patients with hip OA secondary to acetabular dysplasia diagnosed at the department of orthopedic surgery of university hospital from April 2013 to June 2015 participated in this study. The inclusion criterion was as follows: 20-65 years old, diagnosis of hip OA up to advanced stage (marked joint space narrowing), and the ability to walk without an assistive device and to maintain OLS for at least 10 seconds. OA severity was determined by the orthopedic surgeons based on the Japanese Orthopaedic Association classification of hip OA. Patients with history of previous hip surgeries, and neurologic or other conditions that affected OLS and gait were excluded. Our study included only female patients since the available study population was gender-biased $(6.9 \%$ men $)$, similar to previous studies [15]. Many of the patients had bilateral hip OA, the side with more severe radiographic OA change was analyzed. All participants provided informed consent, and our ethics committee approved the protocol.

\subsection{Radiographic assessment}

A single examiner measured minimum joint space width (mJSW) to assess joint degeneration, Sharp angle, lateral center edge (CE) angle, acetabular head index (AHI), and acetabular roof obliquity (ARO) to assess morphologic abnormalities using a standardized supine anteroposterior digital 
radiograph. The radiographs were obtained in a standardized manner by the same skilled radiology technicians, within 30 days prior to the clinical, OLS, and gait assessment. These measurements had high inter- and intrarater reliability [16,17], and are commonly used to diagnose dysplasia and OA [17]. Images were reviewed on Centricity Enterprise Web, version 3.0 (GE Health care, Buckinghamshire, England). The intrarater reliability [intraclass correlation (ICC) 1,1] of the measurement and standard error of the measurement (SEM) for 20 randomly selected radiographic assessments were $0.99,0.14$ (mJSW; ICC, SEM); 0.97, 1.02 (Sharp angle); 0.98, 1.23 (CE angle); 0.98, 1.36 (AHI); and 0.95,1.54 (ARO), respectively.

\subsection{Pain assessment}

The average hip pain intensity in the last 3 months was assessed on a $100-\mathrm{mm}$ visual analog scale, where 0 was no pain and 100 was the worst imaginable pain.

\subsection{Hip ROM test}

A single examiner conducted passive ROM test. Passive hip ROM was measured using a standard two-arm goniometer (Sakai medical Co., Ltd, Tokyo, Japan) in accordance with previous studies [18].

Patient's position for each ROM test was as follows: hip flexion, supine with knee flexion; hip abduction, supine with the contralateral hip positioned in $10^{\circ}$ abduction to stabilize the pelvis; hip adduction, supine with the contralateral hip positioned in slight flexion; hip external rotation and internal rotation, prone with $90^{\circ}$ of knee flexion. The hip extension ROM was measured in the supine position with the hip joints positioned at the edge of the treatment table and the contralateral hip was flexed to flatten the lumbar spine and stabilize the pelvis. The angle between the ipsilateral femur and the horizontal line was measured with the ipsilateral hip and knee hanging freely [18]. A stabilization belt was applied across the pelvis and contralateral thigh during rotation and flexion ROM tests, respectively. The end of ROM was defined as the point at which the examiner felt a firm end feeling at which patient pain restricted further movement [18]. ROM was recorded to the nearest $1^{\circ}$ and was measured once. The ICC (1,1) and SEM for the ROM tests were 0.98, 2.24 (flexion; ICC, SEM); 0.82, 
1.46 (extension); 0.90, 1.99 (abduction); 0.89, 0.95 (adduction); 0.99, 0.98 (external rotation); and 0.99, 1.35 (internal rotation), respectively.

\subsection{Hip muscle strength test}

The maximal isometric muscle strength of hip flexion, extension, abduction, external rotation, and internal rotation were measured using a handheld dynamometer ( $\mu$ TAS F-1: Anima Co., Ltd, Tokyo, Japan) by one examiner, as previously reported $[18,19]$.

Patient's position for each muscle test was as follows: hip flexion, sitting on a treatment table with $90^{\circ}$ of hip and knee flexion; hip extension, supine with $20^{\circ}$ of hip flexion and $0^{\circ}$ of knee flexion; abduction, supine with both hips in a neutral position; hip rotations, prone with $90^{\circ}$ of knee flexion. To stabilize the body and pelvis, patients were instructed to hold the edge of the treatment table, and a stabilization belt was applied across the pelvis or contralateral thigh during hip extension and rotation tests or abduction test, respectively. The sensor pad of the handheld dynamometer was placed $5 \mathrm{~cm}$ above the patella for flexion and abduction tests, and $5 \mathrm{~cm}$ above the malleolus for extension and rotations tests. For each strength test, all patients performed two maximal trials for 3 seconds after few practice trials. The mean of the two trials was used for analysis. Each strength value and lever arm was converted into a ratio of torque to body weight $(\mathrm{Nm} / \mathrm{kg})$. The ICC $(1,1)$ and SEM for the muscle strength tests were 0.93, 13.03 (flexion; ICC, SEM); 0.96, 3.34 (extension); 0.93, 9.95 (abduction); 0.98,3.34 (external rotation); and 0.85, 9.03 (internal rotation), respectively.

\subsection{Motion analysis}

Body kinematics was recorded using Vicon motion system (Vicon Motion Systems Ltd., Oxford, England) at a sampling rate of $200 \mathrm{~Hz}$ and a fourth-order Butterworth low-pass filter with a $6 \mathrm{~Hz}$ cutoff, and with force plates (Kistler Japan Co., Ltd. Tokyo, Japan) at a sampling rate of $1000 \mathrm{~Hz}$ and a lowpass filter $(20 \mathrm{~Hz})$, respectively. Four reflective markers were placed at the bilateral anterior and posterior superior iliac spine of the pelvic segment. Three markers were placed at the superior aspect of the greater trochanter and the medial and lateral femoral condyles of the thigh segment. The shank 
segment had 4 markers placed at the medial and lateral femoral condyles and the medial and lateral malleoli. The three-dimensional hip joint angles were calculated using BodyBuilder software (Vicon Motion Systems Ltd., Oxford, England).

The OLS task was measured by reference to review article on knee OA [20]. Participants stood with both feet on the force plates and hands folded on the abdomen; they then raised one leg about 10 $\mathrm{cm}$ from the floor. The subjects were asked to maintain OLS comfortably for at least 10 seconds. Participants performed several practice trials before the testing. Only the task with the affected leg supported was analyzed. Balance and the three-dimensional hip joint angles during OLS were measured during the middle 5 seconds of OLS. The mean value was taken as hip joint angle. Balance was evaluated as the range of center of pressure in the anteroposterior and mediolateral directions, and root mean square area of center of pressure. Hip joint angles were also calculated at the foot-off of the raising leg (timing of decrease in loading on the force plate to $<5 \%$ body weight). The changes in hip joint angles were calculated from the mean values of 3 seconds of two-leg standing.

For the gait task, the participants walked barefoot along a 7-m walkway at their usual speed after several practice trials. The gait speed and peak of three-dimensional hip joint angles during a gait cycle were calculated. The mean values from three successful trials were calculated and used for analysis.

\subsection{Statistical analysis}

The crude bivariate relationship between dependent variables (balance, gait speed, and hip angles in OLS and gait) and independent variables [age, body mass index (BMI), radiographic variables, pain, and hip ROM and muscle strength] were examined using Pearson's correlation coefficients. Decrease in hip motion in a certain direction during motion is not necessarily caused by decrease in passive ROM or hip muscle strength in the same direction (e.g., hip abductor muscle weakness is associated with decrease in hip extension during gait in patients with total hip arthroplasty [THA]) [21]. Therefore, all independent variables were included in the correlation analyses. The Shapiro-Wilk test was used to determine whether the datasets followed a normal distribution.

To determine the independent contribution of each category of variables in OLS and gait, separate forward-backward stepwise multiple regression analyses were performed as appropriate. 
Multicollinearity was examined using the absolute values of the correlation coefficients ( $|\mathbf{r}|)$ and variance inflation factors (VIF), where $|r|>0.7$ and VIF $>10$ indicate multicollinearity [22]. Statistical significance was determined as $P<0.05$. Statistical analyses were performed using IBM SPSS Statistics, version 19.0 (IBM Japan Ltd., Tokyo, Japan).

\section{Results}

The demographic, radiographic, pain, ROM, and muscle strength data are shown in Table 1. Ensemble average of hip angle waveform during OLS and gait are shown in Fig 1 and Fig 2; on average, the hip joint was flexed, adducted, and internally rotated during OLS.

\subsection{One-leg standing}

No related factors were found in balance measures during OLS (Table 2). Decreased hip muscle strength was significantly correlated with hip flexion while maintaining OLS. Decreased hip muscle strength was also significantly correlated with hip internal rotation while maintaining OLS.

At the foot-off in OLS, decreased AHI was significantly correlated with hip extension. Multiple regression analysis revealed that pain was independently associated with hip abduction.

\subsection{Gait}

BMI, pain, and all hip muscle strength were significantly correlated with gait speed (Table 3). Multicollinearity was indicated when all hip muscle strengths were included in the multiple regression analysis; therefore, variables (i.e., flexion and internal rotation) that caused multicollinearity in muscle strength were excepted. Multiple regression analysis revealed that increased pain and decreased hip extension strength were independently associated with slower gait speed. Decrease in hip ROM was significantly correlated with decreased hip extension during gait. Multiple regression analysis revealed that decreased hip adduction ROM was significantly associated with decreased peak hip adduction 
during gait. Decreased hip external rotation ROM was significantly correlated with decreased hip external rotation during gait. Multiple regression analysis showed that decreased hip internal rotation ROM remained a significant factor associated with decreased hip internal rotation during gait.

All of the aforementioned associations in OLS and gait were independent from radiographic degeneration. Although adaptability of the multiple regression formulas was not high, we took particular note of statistical significance of partial regression coefficients because we focused on the degree of influence of independent variables on dependent variable rather than the accuracy of the prediction formulas.

\section{Discussion}

The purpose of this study was to determine how each of the radiographic and clinical factors relates to performance and hip kinematic changes during OLS and gait in patients with mild-to-moderate secondary hip OA. AHI, pain, and hip impairments were associated with OLS and gait, independent from age and radiographic evidence of degeneration. However, factors related to ability and hip kinematics were distinctly different according to task.

No factors were related to the balance measures during static OLS. Multi-segment postural control strategy and the ankle joint are believed to contribute to balance control in static OLS [23,24]. Other body parts may compensate for the hip joint for postural control in patients with hip OA. Decreased hip muscle strength was significantly correlated with angle changes into hip flexion and internal rotation while maintaining OLS. This finding may be related to previous research describing increased pelvic anterior tilt (i.e., hip flexion) in patients with hip OA [25]. Hip joint angle was reported to change slightly toward extension $\left(1.2^{\circ}\right)$, adduction $\left(3.0^{\circ}\right)$, and internal rotation $\left(2.2^{\circ}\right)$ during OLS in healthy young individuals [26]. The flexed and internal rotated hip positions resulted in increased load-transfer area [27]. Patients with hip muscle weakness may tend to load in the more structurally stable hip position.

At foot-off in OLS, hip abduction was associated with pain rather than muscle weakness. The previous study indicated that patients with end-stage hip OA tended to displace their pelvis and trunk 
as an anticipatory postural adjustment to prevent increase of pain before foot-off in the lateral step motion [28]. Since an abducted hip position can increase load-transfer area, patients with hip pain may move their hips into an abducted position to reduce hip stress anticipatory to initiation of OLS. Importantly, decreased AHI was associated with hip extension at foot-off in OLS. Decreased AHI has been correlated with increased peak contact pressure in the hip [14], and extended hip position causes decreased load-transfer area [25]. Our findings indicate that patients with lower AHI tend to move the hip joint into a position that increases hip contact pressure.

Pain and lower hip extension strength were associated with slower gait speed. Patients with hip OA would control gait speed to reduce load on their painful hips. The association between hip extension muscle strength and gait speed was in consistency with the previous studies [10,11]. Muscle force, especially from hip extensors and ankle planter flexors, are critical to forward progression during gait [29]; thus, the associations in the current study seem reasonable.

Passive hip ROM was associated with peak hip angles during gait. Although there are no studies on factors related to three-dimensional hip angle during gait in patients with hip OA, reduced hip extension during gait has been identified as an important marker of hip OA progression $[8,9,30]$. We did not evaluate cartilage lesions by magnetic resonance imaging; however, it is possible that cartilage damage could negatively influence passive hip ROM and limit hip extension during gait as has been reported in a previous study [30]. Tsukagoshi et al. [21] demonstrated that pain, hip abductor muscle strength, and passive hip extension ROM were associated with peak hip extension during gait in the patients with THA. Since THA is performed for end-stage hip OA, these patients are assumed to have more severe impairments than those with mild-to-moderate hip OA. The influence of muscle weakness on gait may become more apparent in patients with more advanced hip OA. Gait is a relativelydynamic task that requires three-dimensional hip excursion, whereas OLS is a relatively-static task with less need for passive hip ROMs.

This study has certain limitations. Overall, the correlation coefficients were not strong. This suggests that factors that were not measured in this study were also associated with OLS and gait. Hip morphologic abnormalities were not evaluated in three-dimensions. Since anteroposterior radiographs are most commonly used for clinical diagnosis, knowledge about the association between variables assessed from anteroposterior radiographs and physical function would be clinically useful. However, 
future studies are necessary to evaluate hip morphologic abnormalities in more detail. Hip flexion ROM was measured in a knee flexed position; thus, the effect of hamstrings shortening was unclear. Hip angle changes in OLS were different from those of young healthy subjects in the previous study [26]; however, knowledge of an association in the age-matched healthy subjects would be needed to determine a patient-specific association. Additionally, this study included patients with mild-tomoderate secondary hip OA. Thus, the identified associations might not be applicable to patients with end-stage hip OA or primary hip OA. In patients with end-stage hip OA, more severe bone deformities and hip impairments may have greater influence on physical function. Finally, since this study was cross-sectional, causal relationships can only be inferred. Future studies with longitudinal designs are needed to determine the effect of symptoms and impairments on OLS and gait.

\section{Conclusions}

While maintaining OLS, reduced hip muscle strength was associated with hip angle changes. At foot-off in OLS, reduced AHI and increased pain were associated with hip angle changes in the sagittal and frontal planes. Decreased passive hip ROM was associated with reduced hip peak angles during gait, although pain and hip extension muscle strength were significantly related to gait speed. These associations were independent from age and radiographic degeneration. Although the causal relationship requires careful interpretation, the findings of this study may be useful for clinicians who target maintaining or improving hip motion during OLS and gait in patients with mild-to-moderate secondary hip OA.

\section{Acknowledgements}

We wish to thank all volunteers who took part in this study for their participation. This study was supported by the JSPS KAKENHI Grant-in-Aid for Scientific Research (C) (24500578). We would like to thank Junji Katsuhira for his assistance in the kinematic and kinetic analysis. The work reported 
in this manuscript has not received financial support from any commercial source.

Conflict of interest statement: None of the authors have any conflicts of interest associated with this study.

\section{References}

[1] Jacobsen S, Sonne-Holm S. Hip dysplasia: a significant risk factor for the development of hip osteoarthritis. A cross-sectional survey. Rheumatology 2005;44:211-8.

[2] Sandell LJ. Etiology of osteoarthritis: genetics and synovial joint development. Nat Rev Rheumatol 2012;8:77-89.

[3] Inoue S, Ohya Y, Tudor-Locke C, Tanaka S, Yoshiike N, Shimomitsu T. Time trends for stepdetermined physical activity among Japanese adults. Med Sci Sports Exerc 2011;43:1913-9.

[4] Chu CR, Millis MB, Olson SA. Osteoarthritis: From palliation to prevention: AOA critical issues. J Bone Joint Surg Am 2014;96:e130.

[5] Edwards MH, van der Pas S, Denkinger MD, Parsons C, Jameson KA, Schaap L, et al. Relationships between physical performance and knee and hip osteoarthritis: findings from the European project on osteoarthritis (EPOSA). Age Aging 2014;43:806-13.

[6] Sulsky SI, Carlton L, Bockmann F, Ellegast R, Glitsch U, Hartmann B, et al. Epidemiological evidence for work load as a risk factor for osteoarthritis of the hip: a systematic review. Plos One 2012;7:e31521.

[7] Nunley RM, Prather H, Hunt D, Schoenecker PL, Clohisy JC. Clinical presentation of symptomatic acetabular dysplasia in skeletally mature patients. J Bone Joint Surg Am 2011;93:1721.

[8] Eitzen I, Fernandes L, Nordsletten L, Risberg MA. Sagittal plane gait characteristics in hip osteoarthritis patients with mild to moderate symptoms compared to healthy controls; a cross- 
sectional study. BMC Musculosketel Disord 2012;13:258.

[9] Watelain E, Dujardin F, Babier F, Dubois D, Allard P. Pelvic and lower limb compensatory actions of subjects in an early stage of hip osteoarthritis. Arch Phys Med Rehabil 2001;82:1705-11.

[10]Pua YH, Wrigley TV, Collins M, Cowan SM, Bennell KL. Association of physical performance with muscle strength and hip range of motion in hip osteoarthritis. Arthritis Rheum 2009;61:44250.

[11]Pua YH, Wrigley TV, Cowan SM, Bennell KL. Hip flexion range of motion and physical function in hip osteoarthritis: Mediating effects of hip extensor strength and pain. Arthritis Rheum 2009;61:633-40.

[12]Hurwitz DE, Hulet CH, Andriacchi TP, Rosenberg AG, Galante JO. Gait compensations in patients with osteoarthritis of the hip and their relationship to pain and passive hip motion. $\mathrm{J}$ Orthop Res 1997;15:629-35.

[13]Zeni J Jr, Pozzi F, Abujaber S, Miller L. Relationship between physical impairments and movement patterns during gait in patients with end-stage hip osteoarthritis. J Orthop Res $2015 ; 33: 382-9$.

[14] Genda E, Iwasaki N, Li G, MacWilliams BA, Barrance PJ, Chao EYS. Normal hip joint contact pressure distribution in single-leg standing. Effect of gender and anatomic parameters. J Biomech 2001;34:895-905.

[15] Aoki H, Nagao Y, Ishii S, Masuda T, Beppu M. Acetabular and proximal femoral alignment in patients with osteoarthritis of the dysplasic hip and its influence on the progression of disease. $\mathrm{J}$ Bone Joint Surg Br 2010;92-B:1703-9.

[16]Nelitz M, Guenther KP, Gunkel S, Puhl W. Reliability of radiological measurements in the assessment of hip dysplasia in adults. Br J Radiol 1999;72:331-4.

[17]Reijman M, Hazes JMW, Koes BW, Verhagen AP, Bierma-Zeinstra SMA. Validity, reliability, and applicability of seven definitions of hip osteoarthritis used in epidemiological studies: a systematic appraisal. Ann Rheum Dis 2004;63:226-32.

[18]Pua YH, Wrigley TW, Cowan SM, Bennell KL. Intrarater test-retest reliability of hip range of motion and hip muscle strength measurements in person with hip osteoarthritis. Arch Phys Med Rehabil 2008;89:1146-54. 
[19]Bieler T, Magnusson SP, Kjaer M, Beyer N. Intra-rater reliability and agreement of muscle strength, power and functional performance measures in patients with hip osteoarthritis. J Rehabil Med 2014;46:997-1005.

[20]Lawson T, Morrison A, Blaxland S, Wenman M, Schmidt CG, Hunt MA. Laboratory-based measurement of standing balance in individuals with knee osteoarthritis: A systematic review. Clin Biomech 2015;30:330-42.

[21]Tsukagoshi R, Tateuchi H, Fukumoto Y, et al. Factors associated with restricted hip extension during gait in women after total hip arthroplasty. Hip Int 2015;25:543-548.

[22]Dormann CF, Elith J, Bacher S, Buchmann C, Carl G, Carré G, et al. Collinearity: a review of methods to deal with it and a simulation study evaluating their performance. Ecography 2013;36:27-46.

[23]Federolf P, Roos L, Nigg BM. Analysis of the multi-segmental postural movement strategies utilized in bipedal, tandem and one-leg stance as quantified by a principal component decomposition of marker coordinates. J Biomech 2013;46:2626-33.

[24]Riemann BL, Myers JB, Lephart SM. Comparison of the ankle, knee, hip, and trunk corrective action shown during single-leg stance on firm, foam, and multiaxial surfaces. Arch Phys Med Rehabil 2003;84:90-5.

[25] Yoshimoto H, Sato S, Masuda T, Kanno T, Shundo M, Hyakumachi T, et al. Spinopelvic alignment in patients with osteoarthritis of the hip. Spine 2005;30:1650-7.

[26] Tateuchi H, Wada O, Ichihashi N. Effects of calcaneal eversion on three-dimensional kinematics of the hip, pelvis and thorax in unilateral weight bearing. Hum Mov Sci 2011;30:566-73.

[27]Levangie PK. The hip complex. In: Levangie PK, Norkin CC, editor. Joint structure and function: A comprehensive analysis. 4th ed. Philadelphia : F.A. Davis Company; 2005, p. 355-91.

[28] Tateuchi H, Ichihashi N, Shinya M, Oda S. Anticipatory postural adjustments during lateral step motion in patients with hip osteoarthritis. J Appl Biomech 2011;27:32-9.

[29]Liu MQ, Anderson FC, Schwartz MH, Delp SL. Muscle contributions to support and progression over a range of walking speeds. J Biomech 2008;41:243-52.

[30] Kumar D, Wyatt C, Chiba K, et al. Anatomic correlations of reduced hip extension during walking in individuals with mild-moderate radiographic hip osteoarthritis. J Orthop Res 2015;33:527-34. 


\section{Figure legends}

Fig 1. Ensemble average waveforms of hip angle during one-leg standing in the sagittal (a), frontal (b), and transversal (c) planes. Positive values represent flexion (a), abduction (b), and external rotation (c). Solid line: average angular trajectories. Dotted line: plotted average trajectory $\pm 1 \mathrm{SD}$. Extracted data from the 3 seconds prior to the foot-off (time 0; gray bar) to 4 seconds after foot-off are displayed.

Fig 2. Ensemble average waveforms of hip angle during gait in the sagittal (a), frontal (b), and transversal (c) planes. Positive values represent flexion (a), abduction (b), and external rotation (c). Solid line: average angular trajectories. Dotted line: plotted average trajectory $\pm 1 \mathrm{SD}$. 


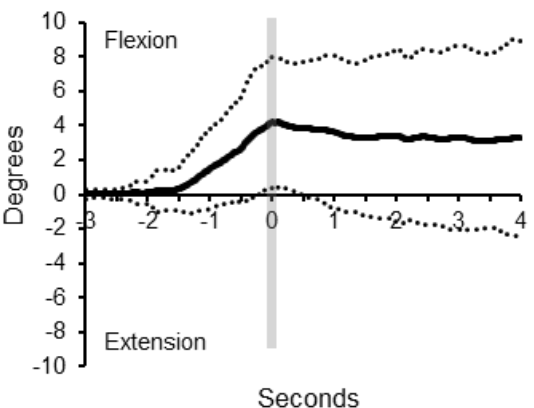

a.

Fig 1.

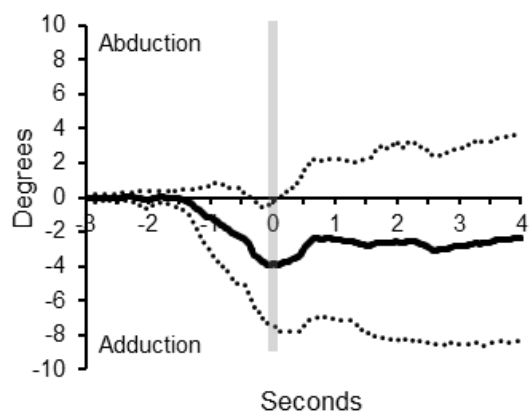

b.

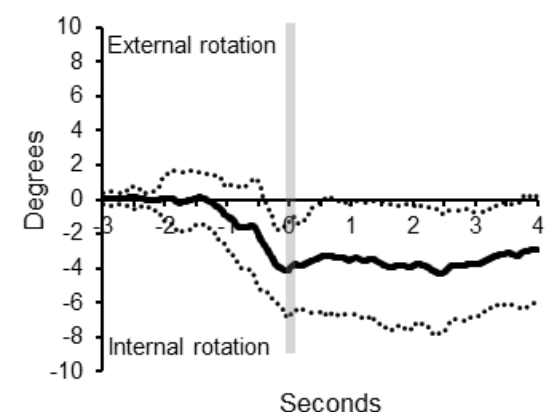

c.

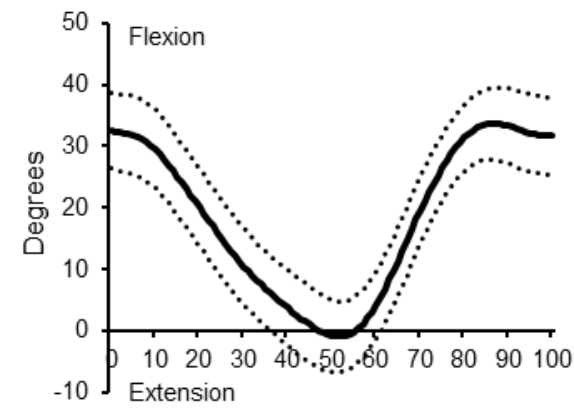

Percent gait cycle

a.

Fig 2.

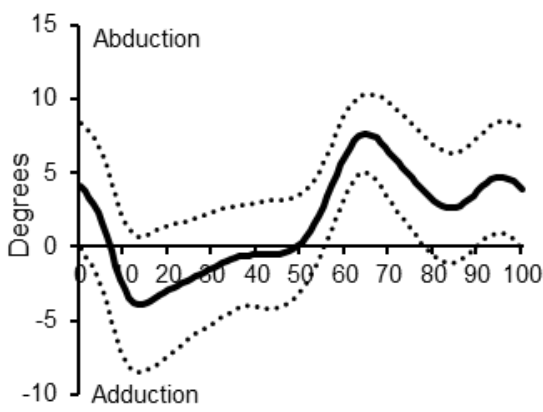

Percent gait cycle

b.

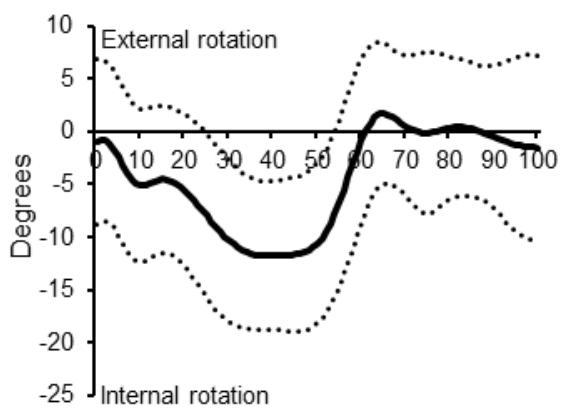

Percent gait cycle 
Table1 Demographic, radiographic, ROM, pain, and muscle strength data $(\mathrm{n}=55)$

\begin{tabular}{|c|c|c|}
\hline & Mean \pm SD & Range \\
\hline Age, years & $47.9 \pm 10.4$ & $22-65$ \\
\hline Height, m & $1.57 \pm 5.6$ & $1.45-1.72$ \\
\hline Weight, kg & $55.2 \pm 9.9$ & $38.5-79.9$ \\
\hline Body mass index, $\mathrm{kg} / \mathrm{m}^{2}$ & $22.5 \pm 4.0$ & $15.9-32.7$ \\
\hline mJSW, mm & $3.5 \pm 1.3$ & $0.4-6.0$ \\
\hline Sharp angle, degrees & $44.8 \pm 6.3$ & $31.8-68.9$ \\
\hline $\mathrm{CE}$ angle, degrees & $23.8 \pm 11.3$ & $0.6-52.8$ \\
\hline AHI & $74.2 \pm 11.1$ & $53.8-96.1$ \\
\hline ARO, degrees & $21.8 \pm 7.9$ & $4.8-35.5$ \\
\hline Pain (VAS), mm & $42.2 \pm 27.2$ & $0.0-97.0$ \\
\hline \multicolumn{3}{|l|}{ Hip ROM, degrees } \\
\hline Flexion & $112.2 \pm 14.2$ & $72.0-134.0$ \\
\hline Extension & $11.6 \pm 3.4$ & $3.0-19.0$ \\
\hline Abduction & $23.3 \pm 5.9$ & $10.0-32.0$ \\
\hline Adduction & $15.3 \pm 3.6$ & $4.0-22.0$ \\
\hline External rotation & $24.3 \pm 11.7$ & $0.0-50.0$ \\
\hline Internal rotation & $41.0 \pm 14.0$ & $14.0-73.0$ \\
\hline \multicolumn{3}{|c|}{ Hip muscle strength, $\mathrm{Nm} / \mathrm{kg}$} \\
\hline Flexion & $0.86 \pm 0.25$ & $0.42-1.66$ \\
\hline Extension & $1.45 \pm 0.57$ & $0.51-3.30$ \\
\hline Abduction & $0.74 \pm 0.21$ & $0.37-1.37$ \\
\hline External rotation & $0.36 \pm 0.12$ & $0.14-0.66$ \\
\hline Internal rotation & $0.32 \pm 0.12$ & $0.11-0.79$ \\
\hline
\end{tabular}

(Footnotes for Table 1)

Abbreviations: VAS, visual analog scale 
Table2 Bivariate correlation and multiple regression analyses of dependent variables related to one-leg standing $(\mathrm{n}=55)$

\begin{tabular}{|c|c|c|c|c|}
\hline & \multirow{2}{*}{ Mean \pm SD } & Bivariate correlation analyses* & \multicolumn{2}{|c|}{ Multiple regression analyses } \\
\hline & & Correlation coefficients $r$, and $P$-value & $\begin{array}{l}\text { Standardized } \beta \text { coefficient, } \\
\quad \text { and } P \text {-value }\end{array}$ & Adjusted $\mathrm{R}^{2}$ \\
\hline \multicolumn{5}{|l|}{ Balance measures during OLS } \\
\hline AP range, $\mathrm{cm}$ & $2.58 \pm 1.01$ & - & & \\
\hline ML range, $\mathrm{cm}$ & $2.43 \pm 0.80$ & - & & \\
\hline RMS area, $\mathrm{cm}^{2}$ & $2.60 \pm 1.54$ & - & & \\
\hline \multicolumn{5}{|l|}{ Hip angle during OLS, degrees } \\
\hline Sagittal plane (+: flexion) & $3.07 \pm 4.86$ & $\begin{array}{l}\text { Hip muscle strength [flexion }(-0.27,0.047) \text {, extension }(-0.29 \text {, } \\
0.037) \text {, abduction }(-0.35,0.010) \text {, and } \operatorname{ER}(-0.34,0.013)]\end{array}$ & NA & \\
\hline Frontal plane (+: abduction) & $-3.49 \pm 4.82$ & - & & \\
\hline Transversal plane (+: ER) & $-3.47 \pm 3.77$ & $\begin{array}{l}\text { Hip muscle strength [flexion }(0.29,0.035), \mathrm{ER}(0.28,0.044) \text {, and IR } \\
(0.28,0.042)]\end{array}$ & NA & \\
\hline \multicolumn{5}{|c|}{ Hip angle at foot-off in OLS, degrees } \\
\hline Sagittal plane (+: flexion) & $4.25 \pm 4.05$ & AHI $(0.28,0.038)$ & NA & \\
\hline Frontal plane (+: abduction) & $-4.19 \pm 3.83$ & $\begin{array}{l}\text { Pain }(0.31,0.022) \\
\text { Hip muscle strength }[\operatorname{IR}(-0.27,0.046)]\end{array}$ & Pain: $\beta=0.31, P=0.022$ & 0.08 \\
\hline Transversal plane (+: ER) & $-3.88 \pm 3.67$ & - & & \\
\hline
\end{tabular}

(Footnotes for Table 2)

Abbreviations: AP, anteroposterior; ML, mediolateral; RMS, root mean square; ER, external rotation; IR, internal rotation; NA, not applicable

* Only statistically-significant variables are shown. 
Table3 Bivariate correlation and multiple regression analyses of dependent variables related to gait $(n=55)$

\begin{tabular}{|c|c|c|c|c|}
\hline & \multirow{2}{*}{ Mean \pm SD } & Bivariate correlation analyses* & \multicolumn{2}{|c|}{ Multiple regression analyses } \\
\hline & & Correlation coefficients $r$, and $P$-value & $\begin{array}{c}\text { Standardized } \beta \text { coefficient, } \\
\text { and } P \text {-value }\end{array}$ & Adjusted $\mathrm{R}^{2}$ \\
\hline Gait speed, $\mathrm{m} / \mathrm{sec}$. & $1.14 \pm 0.16$ & $\begin{array}{l}\text { BMI }(-0.31,0.022) \\
\text { Pain }(-0.46,0.000) \\
\text { Hip muscle strength [flexion }(0.46,0.000) \text {, extension }(0.58,0.000) \text {, } \\
\text { abduction }(0.46,0.000), \operatorname{ER}(0.38,0.004) \text {, and IR }(0.39,0.004)]\end{array}$ & $\begin{array}{l}\text { Pain: } \beta=-0.27, P=0.024 \\
\text { Hip muscle strength (extension): } \\
\beta=0.47, P=0.000\end{array}$ & 0.40 \\
\hline \multicolumn{5}{|c|}{ Hip peak angle during gait, degrees } \\
\hline Flexion & $34.80 \pm 5.77$ & - & & \\
\hline Extension & $2.22 \pm 6.11$ & $\begin{array}{l}\text { Hip ROM [flexion }(0.28,0.037) \text {, extension }(0.36,0.006) \text {, abduction } \\
(0.39,0.003), \operatorname{ER}(0.34,0.011)]\end{array}$ & NA & \\
\hline Abduction & $9.54 \pm 3.14$ & - & & \\
\hline Adduction & $3.96 \pm 3.76$ & $\begin{array}{l}\text { BMI }(-0.34,0.011) \\
\text { Pain }(-0.29,0.033) \\
\text { Gait speed }(0.27,0.050) \\
\text { Hip ROM [flexion }(0.35,0.009), \text { extension }(0.30,0.028) \text {, adduction } \\
(0.49,0.000)] \\
\text { Hip muscle strength [abduction }(0.31,0.023)]\end{array}$ & $\begin{array}{l}\text { Hip ROM (adduction): } \\
\beta=0.49, P=0.000\end{array}$ & 0.24 \\
\hline External rotation & $6.26 \pm 5.37$ & Hip ROM [ER $(0.35,0.008)]$ & NA & \\
\hline Internal rotation & $13.23 \pm 6.76$ & $\begin{array}{l}\text { Age }(-0.30,0.029) \\
\text { Hip ROM }[\operatorname{IR}(0.40,0.003)]\end{array}$ & $\begin{array}{l}\text { Hip ROM (IR): } \\
\beta=0.40, P=0.003\end{array}$ & 0.14 \\
\hline
\end{tabular}

(Footnotes for Table 3)

Abbreviations: BMI, body mass index; ER, external rotation; IR, internal rotation; NA, not applicable

* Only statistically-significant variables are shown. 